Aline Nardes dos Santos

Universidade do Vale do Rio dos Sinos, São Leopoldo, RS, Brasil

Rove Luiza de Oliveira Chishman

Universidade do Vale do Rio dos Sinos, São Leopoldo, RS, Brasil

\title{
Modelos culturais e anencefalia: aborto ou antecipação terapêutica de parto?
}

Resumo: Este trabalho tem como objetivo refletir sobre os modelos culturais ligados ao aborto e sua relação com o processo da Arguição de Preceito Fundamental 54-8 (ADPF 54), cuja decisão final autorizou a interrupção de gravidez no caso de fetos anencefálicos.Busca-se uma aproximação entre a noção de modelo cultural, o conceito de frame semântico e o processo de perfilamento. O ensaio reflete sobre a dinâmica dos modelos culturais Ação, Responsabilidade e Punição, no contexto da ADPF 54, mostrando como o posicionamento dos juristas consolida o cenário de gestação de anencéfalo como punição injusta para a gestante. Palavras-chave: Modelos culturais; ADPF 54; Aborto; Antecipação terapêutica de parto; Anencefalia

\section{Introdução}

Os rumos do Direito giram em torno de sua própria coletânea de textos. Isso inclui a metalinguagem dos juristas em obras que compõem a doutrina, as transcrições de depoimentos e os registros de provas nos processos de conhecimento, bem como as atribuições do juiz em sentenças que reverberam na vida de um indivíduo, ou mesmo de uma comunidade inteira. Como instituição social, o Direito reflete, confronta e consolida o modo como uma sociedade vê o mundo, por meio de suas verdades, seus valores, seus modelos de conduta moral e ética.

Este ensaio tem como objetivo refletir sobre os modelos culturais ligados ao aborto e sua relação como processo da Arguição de Preceito Fundamental 54-8 (ADPF 54-8 ou ADPF

\section{(c) (i)}

Esta obra está sob licença Creative Commons. 
54), cuja decisão final autorizou a interrupção de gravidez no caso de fetos anencefálicos. Segundo Tatiane Fagundes (2014), arguições de preceito fundamental têm o objetivo de denunciar a violação de algum preceito fundamental garantido pela Constituição. No caso da ADPF 54, a ação argumentava que criminalizar a interrupção de gestação de feto anencefálico constituía violação de preceitos como Dignidade da Pessoa Humana, Liberdade e Direito à Saúde. Nesse contexto, o ato de se interromper a gestação de um feto anencefálico é perspectivado de maneiras totalmente distintas por juristas e depoentes, dependendo de seu posicionamento a respeito das condições de vida do feto anencefálico e das implicações para a gestação - aspectos que, por sua vez, estão condicionados ao modo como se constituem seus modelos culturais (Roy D'ANDRADE, 1987; Seana COULSON, 1992; 1997; 2001).

Embora este trabalho se restrinja a refletir sobre a dinâmica desses modelos no contexto da anencefalia, vale observar que tal discussão se realiza em um momento no qual as mulheres brasileiras sofrem intensas ameaças aos poucos permissivos legais existentes no que se refere ao aborto. Nesse ínterim, destacamos a tramitação da PEC 181/ 2015, a qual pode vetar a prática do aborto em casos já regulamentados, inclusive em situações de anencefalia e estupro.

Quanto à estrutura deste ensaio, visto que o conceito de modelo cultural está diretamente ligado a abordagens cognitivas da antropologia e da linguística, principalmente à Linguística Cognitiva, primeiramente contextualizamos as noções linguístico-cognitivas de frame semântico (Charles FILLMORE, 1982; 1985) e de perfilamento (Zoltán KÖVECSES, 2006; William CROFT; David CRUSE, 2004), para então elencarmos as aproximações existentes entre esses conceitos e os modelos culturais. Em seguida, tratamos da temática do aborto conforme análises já realizadas por linguistas cognitivos, de forma a relacioná-la aos modelos culturais Ação, Responsabilidade e Punição, propostos por D'Andrade e utilizados por Coulson para analisar crenças ligadas à moralidade do aborto. Finalmente, após contextualizarmos a ADPF 54, refletimos sobre os modelos culturais que entraram em jogo nesse debate.

\section{Frames, perfilamento e modelos culturais}

Não pense em um elefante! Essa é a frase que George Lakoff utiliza em suas aulas sobre frame na Universidade de Berkeley, de modo a propor um exercício bastante simples: não pensar em um elefante. Isso, obviamente, é impossível, visto que a simples menção a um elefante já nos remete automaticamente a todo o conhecimento que temos a respeito desse animal. Tal processo ocorre porque "Qualquer palavra, como elefante, evoca um frame, que pode ser uma imagem ou outros tipos de conhecimento: elefantes são grandes, têm orelhas frouxas e uma tromba, estão associados a circos, e assim por diante. A palavra é definida em relação a esse frame". (LAKOFF, 2004, p. 3, tradução nossa). A explicação do autor é bastante pontual para contextualizar a noção de frame como dispositivo cognitivo que nos permite atribuir significado à linguagem. Pensar (ou tentar, em vão, não pensar) em um elefante resulta em uma ativação de um ou mais frames, conforme a experiência dos falantes em relação a tal mamífero. Essa ideia é o cerne do conceito de frame que se desenvolveu em diversas áreas do conhecimento, inclusive na linguística, por meio da proposta de Fillmore (1982; 1985). Conforme o autor,

A Semântica de Frames oferece um modo particular de se olhar para o significado das palavras, e também um modo de caracterizar princípios para criar novas palavras e frases, para adicionar novos sentidos às palavras, e para juntar os sentidos de elementos textuais ao sentido total do texto. Pelo termo frame tenho em mente qualquer sistema de conceitos relacionados de tal maneira que, para entender qualquer um deles, é 
preciso entender a estrutura que os comporta como um todo; quando um dos itens de tal estrutura é introduzido em um texto ou em uma conversa, todos os outros se tornam automaticamente disponíveis. (FILLMORE, 1982, p. 11, tradução nossa).

Desse modo, em um cenário de transação comercial, por exemplo, pressupõe-se um conhecimento do falante quanto aos elementos possivelmente envolvidos - comprador, vendedor, produto, dinheiro etc. -, os quais constituem elementos constituintes do respectivo frame.

Como observa Jean Gawron (2008, p. 8, tradução nossa), a Semântica de Frames "[...] parte do pressuposto de que sempre há algum conhecimento prévio relativo ao qual uma palavra realiza algum perfilamento/saliência, e relativo ao qual é definida". Nesse contexto, perfilamento corresponde à ideia básica de que uma palavra ou expressão nunca é compreendida isoladamente pelos falantes, mas é vista como uma porção destacada de um mesmo domínio conceptual (CRUSE, 2006, p. 141). Assim, denomina-se perfil a parte do conteúdo conceptual que é salientada em relação ao restante, chamado base. Os meses do ano, por exemplo, evocam a mesma base referente a um ciclo temporal de doze meses, sendo que cada um deles perfila apenas uma porção desse período. Da mesma forma, no caso de um círculo, é possível focar a atenção no diâmetro, no raio ou na circunferência, sendo que cada um desses focos constitui perfilamentos diferentes em relação à mesma base.

Outro exemplo que pode ser pensado em termos de perfilamento é o caso denominado por Fillmore (1982) como contraste através de frames. Esse contraste permite percebermos que os usos de econômico e avarento, bem como de generoso e esbanjador, remetem a escalas diferentes, ou seja, a perfilamentos contra frames bastante diferentes. Desse modo, em usos como Carlos não é avarento; ele é econômico, ou Você não está sendo generoso com seu filho; você está esbanjando dinheiro para satisfazer seus caprichos trazem uma negação não do fato, mas do framing que é colocado em jogo. Dessa forma, o perfilamento é realizado através de frames conforme a perspectiva que o falante deseja estabelecer.

\subsection{O caso do aborto}

No que se refere à temática do aborto, assuntos ligados a essa esfera são bastante interessantes quanto a modos de se conceptualizar a mesma situação de maneiras bastante diferentes. Como observa Coulson (2001, p. 188, tradução nossa), nesse debate, que tem raízes profundas em aspectos socioculturais, "a natureza da relação entre uma mulher e seu feto é uma questão controversa que carrega a moralidade do aborto". Para Kövecses (2006), essa temática é muito emblemática para mostrar como a realidade não está baseada em premissas objetivas, mas sim em construtos que se desenvolvem a partir de verdades relativas - aborto equivale a assassinato? Fetos são conjuntos de células ou bebês não nascidos? Essas diferentes formas de se conceptualizar um ato de aborto têm implicações morais e consequências reais no que se refere à liberdade individual das mulheres que, por sua vez, está condicionada ao controle social exercido pelo Direito, em conjunto com outros instrumentos socialmente instituídos. Visto que a interrupção de gestação de anencéfalos, temática abordada em nosso trabalho, suscitou a mesma polêmica característica de discussões sobre a descriminalização do aborto em todos os casos, esta seção objetiva mostrar como o tema do aborto tem sido tratado por linguistas cognitivos, cujas considerações evidenciam a pertinência de discutirmos esse caso específico da ADPF 54, que repercutiu no ordenamento jurídico brasileiro. A noção de modelo cultural também é introduzida, dada a sua compatibilidade com o conceito de frame e sua relevância para as reflexões que constituem este ensaio. 
A primeira menção ao caso do aborto que encontramos, sob uma perspectiva sociocognitiva, é feita por Lakoff (1996), a partir de sua noção ampla de frame, ou framing. No contexto de sua análise dos valores que direcionam a agenda política de liberais e conservadores norte-americanos, o autor considera o aborto como um dos temas que transcendem a esfera individual, manifestando duas formas muito diferentes de se pensar sobre a mesma situação. Lakoff explica que os termos médicos embrião (produto da concepção em estágio inicial, desde o zigoto) e feto (em estágio mais avançado, que já manifesta as características físicas da espécie) nem sempre são claramente diferenciados - geralmente, considera-se que o embrião passa a ser denominado feto entre oito e doze semanas.

Essa fronteira é bastante importante na construção da argumentação dos pró-aborto, que enfatizam o caráter ainda não humano do feto - a expulsão de um agrupamento de células salienta uma perspectiva muito diferente daquela que se estabelece quando se considera esse agrupamento como bebê. Lakoff (1996, p. 264-265, tradução nossa) explica que, no cenário norte-americano, grupos pró-vida frequentemente utilizam bebê para se referirem ao embrião ou feto em qualquer estágio. Dessa forma,

A escolha da palavra bebê impõe a ideia de um ser humano independentemente existente. Enquanto agrupamento de células, embrião e feto mantêm a discussão no domínio médico, bebê move a discussão para o domínio moral. A questão da moralidade do aborto é estabelecida a partir do momento em que as palavras são escolhidas. A remoção intencional de um grupo de células da mãe que não constitui um ser humano independentemente existente, viável ou mesmo reconhecível, não pode ser "assassinato". A palavra "assassinato" não é definida como sendo tal procedimento médico. A morte provocada de um "bebê" - um ser humano independentemente existente - pode ser "assassinato".

Para Lakoff, portanto, as escolhas linguísticas dos falantes nesse contexto de aborto indicam a evocação a frames que perspectivam o mesmo evento de aborto de maneiras diferentes, dependendo das convicções morais de cada um - as quais, pondera o autor, são legítimas, defendidas com profunda sinceridade, refletindo a constituição identitária dos indivíduos que compõem esses grupos.

Croft e Cruse (2004) e Kövecses (2006) analisam o caso do aborto por meio da articulação entre frames e perfilamento, mostrando que tanto embrião quanto feto perfilam a entidade em questão contra o frame Mamífero, em uma hierarquia taxonômica, visto que qualquer filho de mamífero pode ser designado por esses termos. Por outro lado, o uso de uma expressão como bebê não nascido resulta em perfilamentos contra dois frames: o primeiro deles é o de Ser Humano, visto que bebê é usado prototipicamente para designar seres de nossa espécie. O segundo é o frame de Ciclo de Vida Humana, porque bebê não nascido remete ao primeiro estágio de vida de um ser humano (KÖVECSES, 2006), projetando o estágio de vida do feto para um momento posterior ao seu nascimento. Para Croft e Cruse (2004, p. 19, tradução nossa), essas escolhas têm o poder de orientar "[...] o ouvinte em direção à posição política sobre aborto, adotada pelo falante", com o objetivo de convencê-lo de que sua posição é mais bem-fundamentada.

Outro estudo importante para discutirmos essas questões foi realizado por Coulson (1997; 2001). Os resultados de suas investigações, relativos à temática do aborto, são bastante pertinentes, principalmente no que se refere à sua apropriação de modelos culturais. Nesse contexto, modelos culturais podem ser definidos como "frames culturalmente partilhados" (COULSON; Esther PASCUAL, 2006). De acordo com as autoras, o desenvolvimento da noção de modelo cultural está associado ao do frame, principalmente no que tange à proposta de Marvin Minsky (1981), e ao conceito de script, de Roger Schank e Robert

4 Revista Estudos Feministas, Florianópolis, 26(2): e43021 
Abelson (1977). A partir disso, os modelos culturais se estabelecem como estruturas representacionais partilhadas que permeiam linguagem e pensamento (COULSON, 1992).

D'Andrade (1987) deixa claro que os modelos culturais também estão atrelados ao frame fillmoriano, visto que um frame como Transação Comercial implica a compreensão da maneira como determinadas atividades e instituições culturalmente condicionadas funcionam. A partir desse conhecimento partilhado, falantes compreendem diferentes transações comerciais em seu contexto cultural, tais como aluguel, lucro, lojas, promoção etc. Para o autor, esses esquemas são considerados como modelos culturais intersubjetivamente partilhados a partir do momento em que todos os indivíduos de uma comunidade partilham dos mesmos modelos, de modo que interpretações feitas por meio dessas estruturas possam, por vezes, ser consideradas por todos como fatos óbvios, processo que embasa o senso comum que se constitui nesse grupo.

D'Andrade afirma que grande parte desses modelos não é explicitada, em virtude de essas estruturas estarem profundamente enraizadas nos modos como certa comunidade vê o mundo. Dessa forma, os falantes deduzem que todos os seus pares estão familiarizados com os mesmos modelos, de modo que não precisam explicitá-los. Como explica D'Andrade (1987, p. 114, tradução nossa), "Eles usam o modelo, mas não podem produzir uma descrição suficiente do modelo." O autor também explica que tais esquemas também acabam servindo para delimitar aquilo que é considerado normal e anormal em determinado grupo. Assim, nas circunstâncias em que as pessoas não agem conforme esses modelos, são consideradas como "anormais" perante o restante da comunidade.

Observando a sociedade americana, D'Andrade propõe diversos modelos culturais que mostram como a mente dessa população funciona. A partir disso, Coulson (1992; 1997; 2001) apropria-se de três modelos que são essenciais para compreendermos as crenças das pessoas no que se refere à moralidade do aborto, inclusive em casos específicos como o de estupro, que foi estudado por Coulson. Esses modelos denominam-se Ação, Responsabilidade e Punição.

O modelo cultural da Ação refere-se a "[...] um agente com uma intenção, que performa uma ação que tem consequências. No modelo, as intenções causam ações, e ações causam suas consequências pretendidas." (COULSON, 2001, p. 228, tradução nossa). Dessa maneira, inconscientemente, pensa-se que todos os atos humanos são causados por intenções - se alguém abriu uma porta, teve a intenção de abri-la; se uma pessoa fere outra, teve a intenção de causar o ferimento. A autora explica que esse modelo cultural da Ação subjaz à motivação das pessoas em tentar explicar a intenção de alguém ao agir, tenha sido causada por desejos, crenças, necessidades, ou por uma combinação de tudo isso (COULSON, 1992).

Em consequência desse primeiro modelo de Ação, o modelo cultural de Responsabilidade coloca o autor da ação como responsável por quaisquer consequências que esse ato possa ter, sejam positivas ou negativas, dado que suas intenções estariam em consonância com o ato praticado. Os resultados obtidos por Coulson em suas investigações mostram que esses modelos explicam por que uma gravidez pode ser conceptualizada de maneiras diferentes pelos falantes, dependendo das circunstâncias. Por exemplo, se uma mulher engravida após ter sido violentada, o aborto é mais facilmente aceitável, na opinião dos falantes entrevistados por Coulson (1997; 2001), visto que não houve intenção, por parte da mulher, de ter a relação sexual. No entanto, se uma mulher engravidar a partir de uma relação sexual consensual, é muitas vezes considerada como sendo responsável por dar seguimento à gravidez indesejada, que consiste também em sua punição.

Dessa forma, a Punição como terceiro modelo cultural está diretamente relacionada aos modelos anteriores - se uma pessoa agiu de certa maneira, tendo a intenção de fazê-lo, merece punição sempre que a comunidade apreciar as consequências de sua ação de 
maneira negativa. Coulson explica que essa é a lógica subjacente à aceitação, por parte dos falantes, de aborto em caso de estupro, visto que a mulher, tendo sido forçada pelo estuprador ao ato sexual, não é responsável pela gravidez como consequência desse acontecimento. Já que o estuprador é o responsável, atribuir à mulher uma punição de levar a cabo a gravidez é considerado injusto, visto que quem deve ser punido é quem cometeu o crime de estupro. Emerge, assim, um modelo cultural de Punição Injusta (COULSON, 2001).

Esses modelos culturais também mostram que, ao manipular os mesmos esquemas, as pessoas podem manifestar posições bastante diferentes. Por exemplo, Coulson (2001) explora, em seu trabalho, o argumento contra o aborto por parte de uma mulher que é fruto de um estupro. Ela considera que, se sua mãe tivesse praticado aborto, isso resultaria em uma punição injusta para si mesma, visto que o responsável seria o pai biológico, que cometeu o estupro. Tal experiência consolida sua posição como contrária ao aborto em qualquer circunstância, colocando em primeiro plano a proteção ao feto. O argumento é reforçado, evidentemente, porque a depoente projeta o estágio de vida do feto a partir da retomada de sua própria história - aspecto que vai ao encontro da conceptualização de feto contra o frame Ciclo de Vida Humana, como vimos anteriormente.

Essas divergências, inerentes ao debate sobre a descriminalização do aborto em diferentes contextos, mostram como é necessário considerarmos a heterogeneidade que permeia uma comunidade aparentemente homogênea em termos de valores, principalmente se levarmos em conta as reflexões de Clifford Geertz (1973 apud KÖVECSES, 2006, p. 292), que define culturas como "redes de significado". Dessa forma, em uma sociedade como a nossa, diferentes redes se manifestam e se articulam - e por vezes se confrontam - perante as diferenças morais e identitárias que caracterizam cada comunidade. Ao encontro disso, consideramos que as discussões suscitadas pela ADPF 54, em virtude da descriminalização da interrupção de gravidez de anencéfalos, colocou em jogo diferentes perspectivas relativas ao mesmo fato, exigindo, do judiciário, um posicionamento que impactou na legislação brasileira.

\section{ADPF 54: pela antecipação terapêutica de parto de anencéfalos}

A ADPF (Arguição de Descumprimento de Preceito Fundamental) é um instrumento previsto na Constituição (BRASIL, 1988) que foi regulamentado onze anos depois (BRASIL, 1999), com a função institucional de levar, ao Supremo Tribunal Federal, "questões sensíveis, envolvendo risco ou lesão a preceito fundamental ou relevante controvérsia constitucional" (Luís Roberto BARROSO, 2006, p. 243).

No que se refere ao conceito de preceito fundamental, Maria Tereza Souza (2006) pondera que esse termo mostra-se bastante vago no ordenamento jurídico, visto que a expressão não é sinônima de princípio constitucional fundamental - concernente àqueles princípios que compõem os primeiros artigos da Constituição -, apesar de abranger também essa categoria. Barroso (2006) acrescenta que nem todo e qualquer preceito expresso na Constituição pode ser considerado fundamental, de modo que essa questão abre espaço para reflexões no campo da doutrina'. Quanto aos princípios que embasam a petição inicial do processo da ADPF 54, os preceitos fundamentais considerados como violados são relativos ao princípio da dignidade humana (art. $1^{\circ}$ da Constituição), ao direito à liberdade (Art. $5^{\circ}$ ) e ao direito à saúde (Art. $6^{\circ}$ ).

' O campo da doutrina é relativo às obras jurídicas que dispõem sobre teorias e interpretações acerca do ordenamento jurídico (Plácido SILVA, 2014).

6 Revista Estudos Feministas, Florianópolis, 26(2): e43021 
Como revela o trabalho de Fagundes (2014), a petição da ADPF 54-8 é construída a partir da tese de que antecipação terapêutica de parto de feto anencefálico não é aborto. Desse modo, esse caso específico de gestação de anencéfalo deveria permitir a prática da antecipação do parto pelos médicos, em virtude de estar comprovada a impossibilidade de sobrevivência do feto anencéfalo fora do útero por muito tempo. A anencefalia pode ser definida como

[...] um distúrbio de fechamento do tubo neural diagnosticável nas primeiras semanas de gestação. Por diversas razões, o tubo neural do feto não se fecha, deixando o cérebro exposto. O líquido amniótico gradativamente dissolve a massa encefálica, impedindo o desenvolvimento dos hemisférios cerebrais. Não há tratamento, cura ou qualquer possibilidade de sobrevida de um feto com anencefalia. Em mais da metade dos casos, os fetos não resistem à gestação, e os poucos que alcançam o momento do parto sobrevivem minutos ou horas fora do útero. (Debora DINIZ; Ana Cristina VÉLEZ, 2008, p. 648).

Anteriormente à autorização de aborto de feto anencefálico, caso houvesse interrupção de gestação de anencéfalo provocada pela mãe ou por terceiro, o ato seria enquadrado como aborto, prática ilícita tipificada pelos artigos 124 a 127 do Código Penal, os quais o categorizam como Crime Contra a Vida:

Aborto provocado pela gestante ou com seu consentimento

Art. 124 - Provocar aborto em si mesma ou consentir que outrem lho provoque:

Pena - detenção, de um a três anos.

Aborto provocado por terceiro

Art. 125 - Provocar aborto, sem o consentimento da gestante:

Pena - reclusão, de três a dez anos.

Art. 126 - Provocar aborto com o consentimento da gestante:

Pena - reclusão, de um a quatro anos.

Parágrafo único. Aplica-se a pena do artigo anterior, se a gestante não é maior de quatorze anos, ou é alienada ou débil mental, ou se o consentimento é obtido mediante fraude, grave ameaça ou violência.

Forma qualificada

Art. 127 - As penas cominadas nos dois artigos anteriores são aumentadas de um terço, se, em consequência do aborto ou dos meios empregados para provocá-lo, a gestante sofre lesão corporal de natureza grave; e são duplicadas, se, por qualquer dessas causas, lhe sobrevém a morte. (BRASIL, 1940).

Quanto a essa tipificação penal, é relevante compararmos a situação atual do Brasil à dos demais países da América Latina, em virtude dos acontecimentos históricos similares que unem algumas dessas nações: conforme pontuam autoras como Nancy Sternbach et al. (1994) e Camilla Siqueira (2015), enquanto se iniciava a segunda onda feminista nos Estados Unidos, países latino-americanos como Brasil, Chile e Argentina, em plena ditadura, articulavam clandestinamente os primeiros movimentos feministas. Dessa forma, há considerável divergência entre a trajetória de conquista de direitos entre o norte global e a América Latina. Segundo dados da ONU (2013), a maior parte das mulheres latino-americanas em idade reprodutiva vive em áreas onde o aborto é restrito ou proibido. Mais especificamente, quanto ao caso da anencefalia, elenca apenas 5 países ${ }^{1}$ latinoamericanos que permitem a interrupção da gestação nos casos de malformação fetal grave, categoria no qual a gravidez de anencéfalos se encaixa. Desses 5 , somente Cuba e Uruguai permitem o aborto sem restrições quanto aos motivos.

${ }^{2}$ Cuba, Honduras, Panamá, Colômbia e Uruguai. 
No que se refere à regulamentação da ADPF no Brasil, é permitido, a confederações sindicais ou entidades de classe de âmbito nacional, propor a referida ação (BRASIL, 1999). Em consonância com esse documento, a petição da ADPF 54 foi protocolada pela Confederação Nacional dos Trabalhadores da Saúde (CNTS), que assume o papel de arguente, representada pela firma de advocacia Luís Roberto Barroso \& Associados. O documento foi destinado ao Ministro Presidente do Supremo Tribunal Federal (STF), entidade que é a "instância máxima do Poder Judiciário brasileiro, a quem compete a 'palavra final' sobre as controvérsias a ele submetidas." (FAGUNDES, 2014, p. 24).

A Figura lesquematiza esse contexto de produção.

\section{Figura 1}

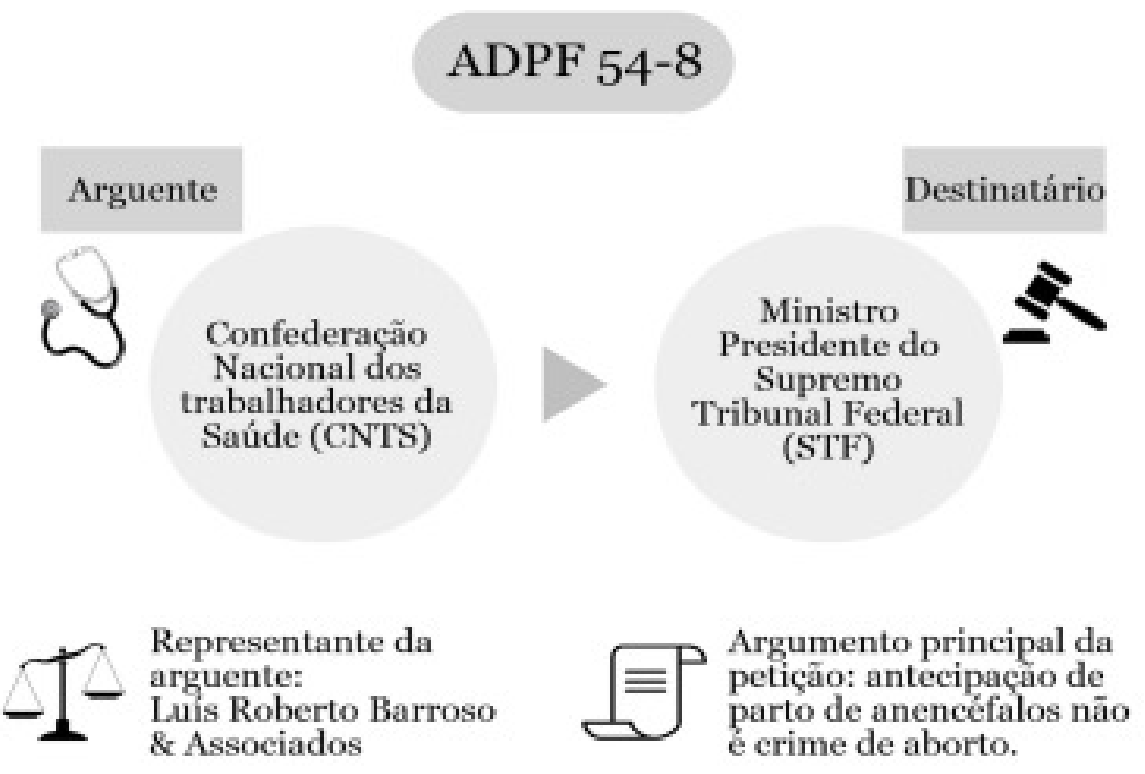

Conforme relatam Tatiana Ferreira (2013) e Flávia Ribeiro (2012), o processo da ADPF, que se iniciou em 2004, foi recebido pelo Ministro Marco Aurélio Mello, o qual concedeu uma liminar que liberava temporariamente a antecipação de parto de anencéfalos. No entanto, após quatro meses, a liminar foi cassada em seção plenária do STF. Entre junho e julho do mesmo ano, houve tentativas massivas de intervenções de entidades religiosas que solicitaram atuar na condição de amicus curiae - quando uma pessoa ou entidade é ouvida mesmo sem ser parte do processo -, tendo todas as petições sido julgadas improcedentes pelo STF: o Ministro Marco Aurélio declarou que este tema, "que sabidamente tem caráter moral, para ele deveria ter uma solução meramente técnica". (Alfredo FLORES, 2005, p. 182).

Entre 2004 e 2005, houve sessões do julgamento, que resultaram na publicação de um acórdão em 2007, o qual suspendia temporariamente processos relativos a pedidos de autorização para antecipar o parto de anencéfalos. Os trabalhos foram retomados somente em 2012 - oito anos após a petição ter sido impetrada -, com a participação de dez ministros do STF. Por oito votos a dois, o pedido de liberação para interrupção de gravidez 
de anencéfalos foi julgado procedente, alterando a jurisprudência do País e tendo eficácia erga omnes, ou seja, tornando-se aplicável a todos os casos relacionados à matéria da ADPF 54. Nos termos do acórdão,

\begin{abstract}
O Tribunal, por maioria e nos termos do voto do Relator ${ }^{3}$, julgou procedente a ação para declarar a inconstitucionalidade da interpretação segundo a qual a interrupção da gravidez de feto anencéfalo é conduta tipificada nos artigos 124, 126, 128, incisos I e II, todos do Código Penal, contra os votos dos Senhores Ministros Gilmar Mendes e Celso de Mello que, julgando-a procedente, acrescentavam condições de diagnóstico de anencefalia especificadas pelo Ministro Celso de Mello; e contra os votos dos Senhores Ministros Ricardo Lewandowski e Cezar Peluso (Presidente), que a julgavam improcedente. (BRASIL, 2012).
\end{abstract}

A Figura 2 traz uma linha do tempo do processo, elencando suas principais etapas.

No que se refere à relevância do referido julgamento para o debate em torno da descriminalização do aborto no País, observamos que esse marco jurisprudencial serviu como embasamento para outra importante decisão publicada no âmbito do STF concernente ao julgamento de um Habeas Corpus que defendeu o afastamento da prisão preventiva de réus denunciados por suposta prática de crime de aborto. $O$ ministro Barroso, que pediu vista dos autos, prolatou voto-vista que foi acompanhado pela maioria dos demais ministros, afastando a prisão preventiva dos réus.

No contexto do voto, é relevante pontuar que a decisão de Barroso foi pautada em relevantes argumentos que justificam a necessidade de descriminalização do aborto, nos três primeiros meses de gestação, como medida mais eficaz para proteger os direitos fundamentais das mulheres e de promover

\title{
Figura 2
}

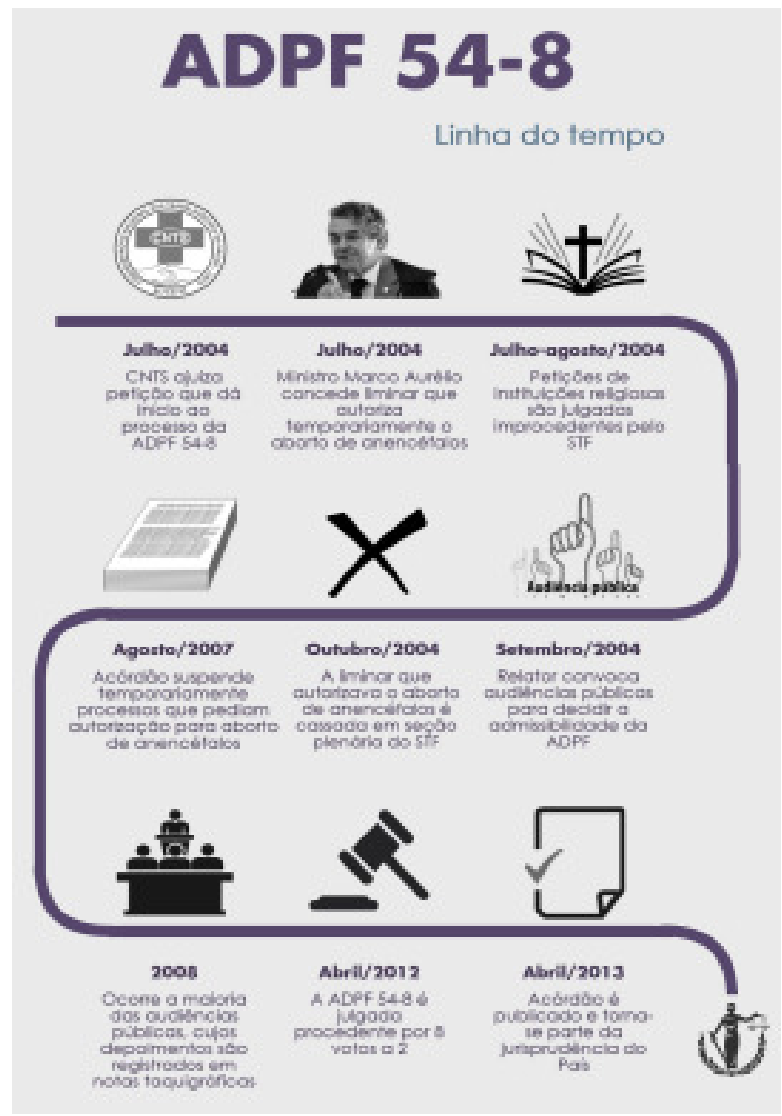
políticas que reduzam efetivamente o número de abortos realizados no País. Conforme defendeu o ministro, a própria constitucionalidade da tipificação do aborto como crime é passível de questionamento, dado que diversos direitos da mulher, previstos na Constituição

\footnotetext{
${ }^{3}$ Segundo Silva (2014, p. 1808), o relator do processo "é o juiz encarregado de expor, por escrito, perante outros juízes, os fundamentos da questão submetida ao veredito deles, para que a julguem". A escolha do relator é feita por sorteio.
} 
de 1988, são violados pelos artigos previstos no Código Penal, cuja redação, vale reiterar, data de 1940. Os direitos elencados por Barroso incluem:

[...] os direitos sexuais e reprodutivos da mulher, que não pode ser obrigada pelo Estado a manter uma gestação indesejada; a autonomia da mulher, que deve conservar o direito de fazer suas escolhas existenciais; a integridade física e psíquica da gestante, que é quem sofre, no seu corpo e no seu psiquismo, os efeitos da gravidez; e a igualdade da mulher, já que homens não engravidam e, portanto, a equiparação plena de gênero depende de se respeitar a vontade da mulher nessa matéria. (BRASIL, 2016, p. 1-2).

Na decisão, o ministro também enfatiza que, além de a criminalização do aborto ultrapassar "os limites constitucionalmente aceitáveis" (BRASIL, 2016, p. 12), a tipificação penal da prática contribui apenas para o aumento de abortos clandestinos no País, fator que impacta na mortalidade feminina em virtude de complicações que ocorrem durante ou após procedimentos realizados de forma insegura - situação que, conforme pontua o voto-vista, configura-se como grave problema de saúde pública. Assim, segundo a decisão de Barroso, a criminalização, na prática, serve apenas como mera "reprovação 'simbólica' de conduta" da mulher (BRASIL, 2016, p. 13-14).

Ao longo do voto, o magistrado ainda enfatiza que a defasagem de tal tipificação penal foi evidenciada pela própria decisão colegiada acerca da ADPF 54, cujos principais argumentos estão calcados em valores constitucionais.

A próxima seção reflete sobre a dinâmica dos modelos culturais envolvidos nesse histórico julgamento.

\subsection{Perfilamentos, aborto e modelos culturais: considerações sobre a ADPF 54}

Retomando brevemente os conceitos encontrados em D'Andrade (1987) e Coulson (1992; 1997; 2001), o modelo cultural de Ação pressupõe uma intenção do agente ao agir de determinada maneira. Se o agente teve a intenção de agir, é então responsável por quaisquer consequências, aspecto que subjaz ao modelo de Responsabilidade. Por consequência, se sua ação teve algum impacto negativo, o agente é visto como merecedor de Punição, terceiro modelo da tríade. Desse modo, é por meio desses modelos que se pode explicar por que uma gestação normal, se interrompida, é vista de maneira negativa por muitas pessoas - nesse caso, muitos grupos consideram que, ao ter uma relação sexual, a mulher teve a intenção de se expor à possibilidade de uma gravidez, a qual se torna uma consequência de sua ação. No entanto, durante o estudo de Coulson, muitos entrevistados consideraram que, se o ato sexual ocorreu sem seu consentimento, caracterizando-se como estupro, a mulher violentada, irresponsável pela ação, não mereceria a punição de ter de prosseguir com uma gravidez resultante de estupro.

É possível verificar que os desdobramentos do processo indicam uma associação entre o modelo cultural de Punição e a gestação de feto anencefálico, em uma situação similar à da gestação resultante de estupro. Porém, ponderamos que as motivações têm uma origem diferente: enquanto, no caso do estupro, a mulher é isenta de responsabilidade por não ter tido a intenção de consumar a relação sexual, no caso da gestação de anencéfalo, não está em jogo a ação da gestante nesse mesmo estágio: a mãe pode ter tido a intenção de engravidar; portanto, o modelo cultural de Ação não se aplica da mesma forma. Além disso, a responsabilidade da mãe sobre a gravidez também não é o foco da discussão, mas sim a sua isenção de responsabilidade quanto ao distúrbio de anencefalia do feto.

No tocante à situação de gestação de feto anencéfalo, consideramos que o processo da ADPF 54 consolida o perfilamento desse tipo de gestação como punição injusta para a 
mãe, visto que, embora ela possa ter tido a intenção de engravidar, não tencionou gestar um feto que é tido como inviável para a vida extrauterina. Desse modo, se a mulher agiu para engravidar, com intenção para tal, a consequência natural deveria ser a gestação de um feto normal, pelo qual ela seria responsável. A partir disso, se a mulher interrompesse sua gravidez, esse ato seria enquadrado como crime de aborto, conforme previsto no Código Penal brasileiro. No entanto, o diagnóstico de anencefalia é uma consequência dissociada das ações da mãe, o que resulta na emergência do modelo de Punição Injusta, que se traduz não apenas por meio da gestação de risco, mas também pelo sofrimento da mãe em levar a cabo uma gravidez em que a mortalidade é comprovadamente certa, seja no momento do nascimento ou pouco tempo depois.

Em suma, a anencefalia, por estar dissociada das Ações da mãe, não implica Responsabilidade para essa agente, o que resulta em Punição Injusta para a gestante, que deve ter garantido o seu direito de interromper a gravidez. Consideramos que a dinâmica diferente entre a manipulação dos modelos culturais no caso de aborto prototípico e no caso desse tipo de interrupção, na esfera jurídica, consolida a diferença entre aborto e antecipação terapêutica de parto, defendida na petição inicial da CNTS.

A Figura 3 ilustra nossa interpretação dos resultados a partir de modelos culturais.

\section{Considerações finais}

Este ensaio teve como objetivo refletir sobre os modelos culturais ligados ao aborto e sua relação com o processo da ADPF 54, aproximando tais modelos dos conceitos de frame e de perfilamento. Desse modo, a primeira parte abordou a noção de frame, bem como as relações entre frame e perfilamento encontradas na literatura. Em seguida, elencamos as considerações de linguistas cognitivos sobre o caso do aborto e os frames e perfilamentos emergentes, para então introduzir os modelos culturais Ação, Responsabilidade e Punição.

A segunda parte concerniu a considerações sobre a relação entre a ADPF 54 e os modelos culturais de D'Andrade (1987). A partir dessas reflexões, consideramos que há ligação direta entre o modelo cultural de Punição e a situação de gravidez de feto anencefálico. No que se refere à emergência do modelo de Punição Injusta, tal cenário aproxima-se da situação de gravidez resultante de estupro, cuja interrupção também é autorizada pelo orde-

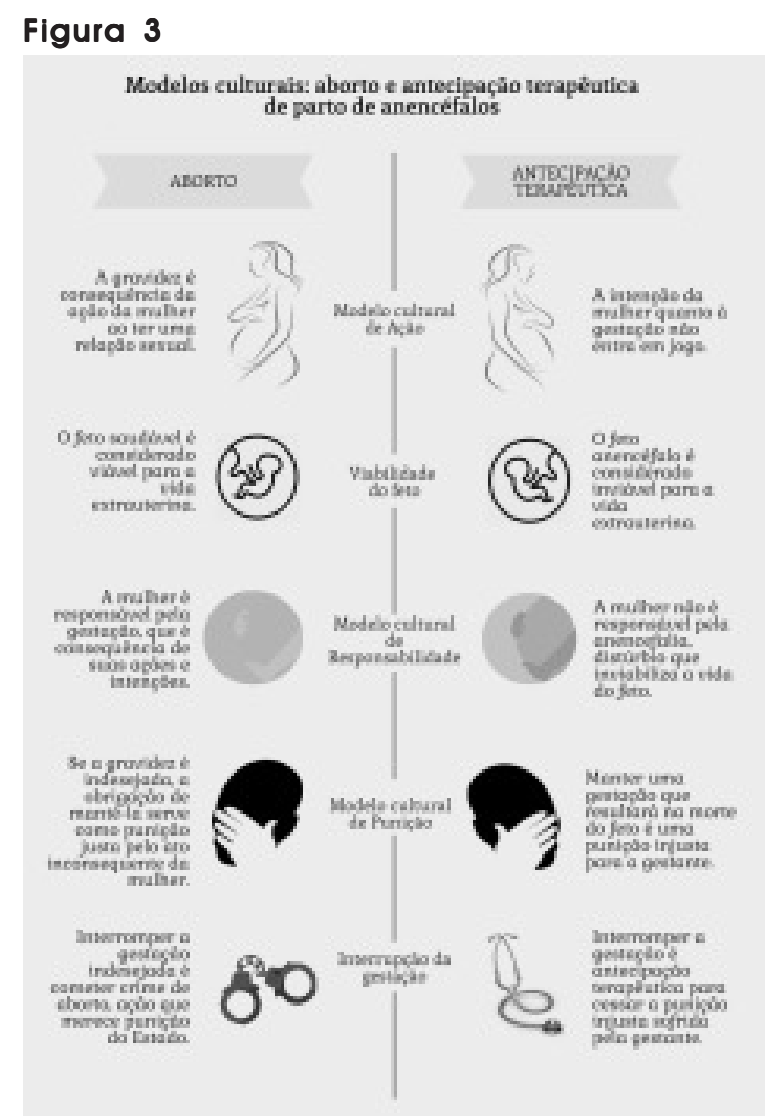


namento jurídico brasileiro. Além disso, essa dinâmica dos modelos culturais distancia-se da situação de crime de aborto, em que uma mulher, ao interromper uma gestação de feto saudável que foi fruto de relação sexual consensual, é considerada como delinquente por grande parte da população e também pelo Estado.

Reiteramos que essa discussão final limita-se às nossas reflexões feitas a partir da exploração do processo da ADPF 54; dessa forma, a relação entre modelos culturais e aborto em contextos mais amplos fica como sugestão para trabalhos posteriores. Ainda quanto à necessidade de trabalhos futuros, consideramos que seria interessante investigar a relação entre esses modelos culturais e os elementos que são perfilados quando falantes manifestam suas crenças e valores, inclusive no que se refere à conceptualização de papéis de gênero.

Por fim, podemos perceber que o Judiciário, no âmbito da autoridade que the é conferida, tem o poder de convencionalizar determinados modelos, conforme os posicionamentos que os juristas acolhem ao proferirem suas decisões, fazendo com que o modo como se usa a linguagem no Direito traga consequências reais ao mundo legalmente estruturado. Nesse contexto, ignora o poder da linguagem quem acredita na objetividade da letra fria da lei: a consolidação de valores morais, dentro e fora da esfera jurídica, está atrelada ao modo como modelos culturais são manipulados e partilhados.

\section{Referências}

BARROSO, Luís R. "Arguição de Descumprimento de Preceito Fundamental: apontamentos sobre seus pressupostos de cabimento". Revista de Direito da Procuradoria Geral, Rio de Janeiro, n. 61, p. 241-259, 2006.

BRASIL. Habeas Corpus 124.306. Voto-vista. Autor: Luís Roberto Barroso. Disponível em: http:/ /www.stf.jus.br/arquivo/cms/noticiaNoticiaStf/anexo/HC124306LRB.pdf. Acesso em: 15/01/ 2016.

Decreto-lei $n^{\circ} 2.848$, de 7 de dezembro de 1940. Código Penal. Disponível em: http://www2.camara.leg.br/legin/fed/declei/1940-1949/decreto-lei-2848-7-dezembro1940-412868-publicacaooriginal-1-pe.html. Acesso em: 04/12/2015.

Constituição (1988). Constituição da República Federativa do Brasil de 1988. Disponível em: http://www.planalto.gov.br/ccivil_03/constituicao/constitui\%C3\%A7ao.htm. Acesso em: 11/08/2014.

. Lei $n^{\circ}$ 9.882, de 3 de dezembro de 1999. Dispõe sobre o processo e julgamento da arguição de descumprimento de preceito fundamental, nos termos do $\S 1^{\circ}$ do art. 102 da Constituição Federal. Disponível em: http://www.planalto.gov.br/ccivil_03/leis/ 19882.htm. Acesso em: 15/01/2015.

. Supremo Tribunal Federal. Arguição de Descumprimento de Preceito Fundamental 54. Requerente: Confederação Nacional dos Trabalhadores da Saúde (CNTS). Relator: Ministro Marco Aurélio Mello. Brasília, 12/04/2012. Disponível em: http://www.stf.jus.br/portal/ processo/verProcessoPeca. asp?id=136389880\&tipoApp=.pdf. Acesso em: 05/12/2015.

COULSON, Seana. Semantic leaps. The role of frame-shifting and conceptual blending in meaning construction. 1997. Dissertation (Doctor of Philosophy in Cognitive Science) Department of Cognitive Science, University of California (UCLA), San Diego. Disponível em:http://www-cogsci.ucsd.edu/research/documents/dissertations/coulson_thesis.pdf. Acesso em: 18/07/2015.

. Is Incest Best? The Role of Pragmatic Scales and Cultural Models in Abortion Rhetoric. Center for Research in Language Newsletter, San Diego, v. 7, n. 2, 1992. Disponível em: http://crl.ucsd.edu/newsletter/7-2/Article1.html. Acesso em: 23/10/2015.

12 Revista Estudos Feministas, Florianópolis, 26(2): e43021 
Semantic leaps. Frame-shifting and conceptual blending in meaning construction. New York: Cambridge University Press, 2001.

PASCUAL, Esther. For the sake of argument. Mourning the unborn and reviving the dead through conceptual blending. Annual Review of Cognitive Linguistics, Amsterdam, v. 4, n. 1, p. 153-181, 2006.

CROFT, William; CRUSE, David A. Cognitive Linguistics. Cambridge: Cambridge University Press, 2004.

CRUSE, David A. A Glossary of Semantics and Pragmatics. Edinburg: Edinburg University Press, 2006.

D'ANDRADE, Roy. "A folk model of the mind". In: QUINN, D.; HOLLAND, N. Cultural models in language and thought. Cambridge: Cambridge University Press, 1987. p. 112-150.

DINIZ, Debora; VÉLEZ, Ana Cristina G. "Aborto na Suprema Corte: o caso da anencefalia no Brasil". Revista Estudos Feministas, Florianópolis, v. 16, n. 2, p. 647-652, 2008. Disponível em: https://periodicos.ufsc.br/index.php/ref/article/view/S0104-026X2008000200019/ 8797. Acesso em: 04/11/2015.

FAGUNDES, Tatiane. A construção argumentativa no gênero discursivo do domínio jurídico: arguição de preceito fundamental 54-8. 2014. Dissertação (Mestrado em Linguística Aplicada) - Programa de Pós-Graduação em Linguística Aplicada, Universidade do Vale do Rio dos Sinos (UNISINOS), São Leopoldo, RS Disponível em: http:// www.repositorio.jesuita.org.br/bitstream/handle/UNISINOS/3617/ Tatiane\%20dos\%20Santos\%20Fagundes_pdf. Acesso em: 25/10/2015.

FERREIRA, Tatiana. A. Análise argumentativa do discurso jurídico: a polêmica sobre o aborto de fetos anencéfalos. 2013. Dissertação (Mestrado em Estudos Linguísticos) - Programa de Pós-Graduação em Estudos Linguísticos. Universidade Federal de Minas Gerais, Belo Horizonte, MG. Disponível em: http://www.bibliotecadigital.ufmg.br/dspace/bitstream/ handle/1843/MGSS-9CDNPZ/an_lise_argumentativa_do_discurso_jur_dico.pdf?sequen $\mathrm{ce}=1$. Acesso em: 04/10/2015.

FILLMORE, C. J. Frame Semantics. In: The Linguistics Society of Korea (Org.). Linguistics in the Morning Calm. Seoul: Hansinh Publishing Co., 1982. p. 111-137.

"Frames and the semantics of understanding". Quaderni di Semantica, vol. 6, n. 2, p. 222-254, 1985

FLORES, Alfredo J. "Uma reflexão sobre a ADPF 54: a condição jurídica do anencéfalo". Quaestio Iuris, Rio de Janeiro, v. 1, n. 2, p. 173-205, dez. 2005. Disponível em: http://www.epublicacoes.uerj.br/index.php/quaestioiuris/article/view/1 1620. Acesso em: 05/12/2015.

GAWRON, Jean M. Frame Semantics. [S.I.], 2008. Disponível em: http://www-rohan.sdsu.edu/ $\sim$ gawron/semantics/course_core/background/minsky frames intro.pdf. Acesso em: 25/ $12 / 2015$.

KÖVECSES, Zoltán. Language, mind and culture. A practical introduction. New York: Oxford University Press, 2006.

LAKOFF, George. Moral politics: how liberals and conservatives think. Chicago: The University of Chicago Press, 1996.

. Don't think of an elephant! Know your values and frame the debate. Vermont: Chelsea Green Publishing, 2004.

MINSKY, Marvin. "A framework for representing knowledge." In: WINSTON, Patrick Henry. (Ed.). The psychology of computer vision. New York: McGraw-Hill Book Company, 1981. p. 211-277.

ORGANIZAÇÃOO DAS NAÇÕES UNIDAS (ONU). World abortion policies 2013. [S.I.], 2013. Disponível em: http://www.un.org/en/development/desa/population/publications/pdf/ policy/WorldAbortionPolicies2013/WorldAbortionPolicies2013_WallChart.pdf. Acesso em: 20/12/2017. 
RIBEIRO, Flávia R. G. "Aborto por anencefalia na mídia brasileira: análise retórica do debate entre as posições 'pró-escolha' e 'pró-vida'". Revista Brasileira de Ciência Política, Brasília, n. 7, p. 83-1 14, jan./abr. 2012. Disponível em: http://periodicos.unb.br/index.php/rbcp/ article/view/6763/5458. Acesso em: 04/12/2015.

SCHANK, Roger C.; ABELSON, Robert P. Scripts, plans, goals, and understanding: An inquiry into human knowledge structures. Hillsdale, NJ: Lawrence Erlbaum, 1977.

SIQUEIRA, Camilla Karla Barbosa. "As três ondas do movimento feminista e suas repercussões no direito brasileiro". In: BEDIN, Gilmar A.; CITTADINO, Gisele G.; ARAÚJO, Florivaldo de. Poder, Cidadania e desenvolvimento no estado democrático de direito. Florianópolis: CONPEDI, 2015. p. 328-354.

SILVA, Plácido. Vocabulário Jurídico. Rio de Janeiro: Forense, 2014.

SOUZA, Maria Tereza B. A. "A Arguição de descumprimento de Preceito Fundamental e a Lei 9.882/99". Revista Urutágua, Maringá, n. 9, abr./maio/jun./jul. 2006. Disponível em: http:/ /www.urutagua.uem.br/009/09souzamaria.htm. Acesso em: 04/12/2015.

STERNBACH, Nancy S. et al. Feministas na América Latina: de Bogotá a San Bernardo. Revista Estudos Feministas, Florianópolis, v. 2, n. 2, p. 255-295, 1994. Disponível em: https:// periodicos.ufsc.br/index.php/ref/article/view/16213. Acesso em: 05/01/2016.

[Recebido em 12/02/2016, reapresentado em 19/01/2018 e aprovado em 23/02/2018]

Cultural Models and Anencephaly: Abortion or Therapeutic Pregnancy Termination? Abstract: This study aims at reflecting on cultural models related to abortion and its connection with the Allegation of Violation of a Fundamental Precept No. 54 (ADPF 54) process, in which the Supreme Court authorized the interruption of pregnancy in cases of anencephaly. It seeks an approximation between the notion of cultural model, the concept of semantic frame and the process of profiling. The assay reflects on the dynamics of the cultural models called Action, Responsibility and Punishment, within the context of ADPF 54, showing how the positioning of the jurists consolidates the scenario of pregnancy in cases of anencephaly as unjust punishment for pregnant women.

Keywords: Cultural models; ADPF 54; Abortion; Therapeutic pregnancy termination; Anencephaly

Aline Nardes dos Santos é mestre em Linguística Aplicada pela Universidade do Vale do Rio dos Sinos (Unisinos) e doutoranda em Linguística Aplicada pela mesma instituição.

Rove Luiza de Oliveira Chishman é doutora em Linguística Aplicada pela Pontifícia Universidade Católica do Rio Grande do Sul (PUC/RS). Professora Titular do Programa de Pós-Graduação em Linguística Aplicada da Universidade do Vale do Rio dos Sinos (Unisinos).

14 Revista Estudos Feministas, Florianópolis, 26(2): e43021 
